
\title{
R Reserach S Suare \\ The Impact of Race, and Insurance Status on Breast Cancer Screening: Results from the Behavioral Risk Factor Surveillance System Data
}

\author{
Salamata Yoda ( $\sim$ sy00001@mix.wvu.edu ) \\ West Virginia University \\ Jennifer Mallow \\ West Virginia University \\ Laurie A. Theeke \\ West Virginia University
}

\section{Research Article}

Keywords: Breast cancer, Breast Cancer Screening, Race, and Health Insurance Coverage.

Posted Date: April 21st, 2021

DOl: https://doi.org/10.21203/rs.3.rs-427806/v1

License: (c) (1) This work is licensed under a Creative Commons Attribution 4.0 International License.

Read Full License 


\section{Abstract \\ Purpose}

Breast cancer is the second major cause of cancer-related death of women in the United States ${ }^{1}$, yet current gaps exist in breast cancer screening for minority women ${ }^{2}$. The purpose of this study is to address these gaps by assessing the relationships among race, health insurance coverage, and breast cancer screening in a nationally representative sample of women.

\section{Design:}

A cross-sectional descriptive analysis of the 2018 BRFSS survey data was used to meet the study purpose. BRFSS participants who declared themselves to be of female sex and who were adults with the age $\geq$ of 40 years were selected for inclusion.

\section{Methods}

Data were analyzed using SPSS version 26. Exploratory and descriptive analyses were performed, followed by comparative analyses based on the variable type. Relationships between race, insurance status, and mammogram screening were examined. Chi-square, logistic, and multinomial logistic regression were used.

\section{Findings:}

The original 2018 BRFSS dataset included 437,436 participants and 145,837 women were selected based on inclusion criteria. Participant age ranged from 40 to 74 years. The majority were White only nonHispanic $(78.1 \%)$, reported having a mammogram in the past two years $(76.1 \%)$, had earned <a 4-year college degree (61.1\%), had an annual income of $<\$ 75,000$ (58.4\%) and married (58.2\%). Less than half had a healthcare plan through an employer (44.9\%) and were employed (40.5\%). Participants who had a plan purchased through an employer or union were more likely to have a mammogram in the past two years when compared with other health coverage. Furthermore, White only, non-Hispanics were 1.25 times more likely and Black only, non-Hispanics were 1.98 times more likely to have a mammogram in the past two years compared to participants from other racial and ethnic groups.

\section{Conclusion}

The findings of this study provide an additional indication that race, and health insurance status do impact breast cancer screening. 


\section{Clinical Relevance:}

Knowledge gained from this study can be used by practicing nurses to educate racial and ethnic minority women on the significance of breast cancer screening and prevention.

\section{Introduction}

Breast cancer is currently the second major cause of cancer-related death for women in the United States

${ }^{1}$. Notwithstanding its limitations, mammography remains the only screening test for breast cancer advocated by the United States Preventive Services Task Force and the American Cancer Society, thus, currently, the most effective screening exam to decrease breast cancer mortality ${ }^{3}$. The American College of Radiology (ACR) has advised yearly mammography screening commencing at age 40 for females with a normal risk of developing breast cancer ${ }^{2}$. Mammogram screening has reliably decreased breast cancer mortality by approximately $40 \%$ since 1990 and most of this improvement is ascribed to early detection ${ }^{2}$. Although the national efforts by the Center for Disease Control and Prevention and the Breast and Cervical Cancer Early Detection Program were effective in increasing breast cancer screening rates, there are still substantial disparities in breast cancer screening utilization and breast cancer mortality among racial and ethnic minority women ${ }^{4}$.

Factors such as paucity of socioeconomic resources and limited access to healthcare have led to inequalities in the care of underprivileged populations ${ }^{5}$. Compared with their White counterparts, racial and ethnic minorities women experience more underinsurance or lack health insurance coverage completely ${ }^{5}$. The disparity in insurance status and the resulting decrease in access to care stems from social determinants of health and results in a lower adherence to breast cancer screening recommendations ${ }^{4}$. Lower rates of screening mammography result in diagnosis of cancer at a later stage disease and impacts survival rates ${ }^{4}$. Recognizing social determinants of health that cause delays in care accessibility may lead to individualized interventions mainly targeted to increase adherence to mammogram screening; hence, improving health outcomes for women who experience health inequality. The purpose of this study is to examine the relationship of race and health insurance coverage on screening for breast cancer by using the data from the Behavioral Risk Factor Surveillance System (BRFSS) survey, in a nationally representative sample of adult women.

\section{Methods}

\section{Data Source, Ethical Conduct of Research}

The BRFSS is a recurrent cross-sectional survey carried out with technical and methodological aid from the Centers for Disease Control and Prevention (CDC) ${ }^{6}$.The BRFSS data was initially devised to assist the nation in its data gathering efforts in order to obtain a comprehensive view of state and local data for health program development. Since 1984, the CDC began to conduct yearly health-related telephone 
survey in the United States and its territories to collect data on health behaviors, chronic diseases, health care accessibility, and the use of health services. State health organizations jointly work together to develop the survey and conduct the interviews themselves or through the assistance of contractors. Participants' samplings are performed through the random digit dialing from commercially accessible phone catalogs. Once consented, participants take part in the survey using Computer-Assisted Telephone Interviews (CATI) system ${ }^{6}$. Cellular surveys use the Telecordia database of telephone exchanges and 1000 banks to arbitrary choose telephone numbers. Once gathered, 2018 data was processed, aggregated, weighted by the CDC and made openly accessible for analysis on the CDC website. The 2018 BRFSS data was retrieved and an analysis of the relationships between race, insurance status, and screening for breast cancer was performed. Due to the de-identified freely available national data used in this analysis, Institutional Review Board review was not sought or required.

\section{The Study Design}

\section{Study Population and Sample}

For the present analysis, the populations of interest were noninstitutionalized adult females $\geq 40$ years since the recommended mammograms screening starts at age 40 . Exclusion criteria included men, women younger than 40 years of age, transgender individuals, institutionalized female population, and women of unknown race.

\section{Measures}

\section{Descriptive Variables}

The current study consisted of female survey participants $\geq 40$ years who responded to questions in the Breast and Cervical Cancer-Screening module of the BRFSS (Sect. 14 of the 2018 survey) ${ }^{6}$.

\section{Age}

Age was collected as a categorical variable and provided in the dataset via the following categories: (40$44,45-49,50-54,55-, 60-64,65-69,70-74)$.

\section{Race}

Race was collected as a categorical variable and provided in the dataset via the following categories: (White, Black, Hispanic, Other (Asian, American Indian or Alaskan Native, Native Hawaiian or others Pacific Islander, others race, multiracial).

\section{Marital status}

Marital status was collected as a categorical variable and provided in the dataset via the following categories: Marital status (Married, Divorced, Widowed, Separated, Never married, A member of an unmarried couple). 


\section{Employment}

Employment was collected as a categorical variable and provided in the dataset via the following categories: (Employed for wages, Self-employed, Out of work for 1 year or more, Out of work for 1 less than 1 year, A homemaker, A student, Retired, Unable to work).

\section{Income}

Income was collected as a categorical variable and provided in the dataset via the following categories: (> \$10,000; $\$ 10,000$ - > \$15,000; $\$ 15,000$ - > \$25,000; $\$ 25,000$ - > \$35,000; $\$ 35,000$ - > \$50,000; $\$ 50,000->\$ 75,000 ; \$ 75,000$ or more).

\section{Education}

Education was collected as a categorical variable and provided in the dataset via the following categories: (Never attended school or only kindergarten, Elementary, Some high school, High school graduate, Some college or technical school, College graduate).

\section{Independent variables}

\section{Primary Health Insurance Coverage}

Primary Health Insurance Coverage was collected as a categorical variable and provided in the dataset via the following categories: (A plan purchased through an employer or union, A plan that you or another family member buys on your own, Medicare, Medicaid or other state program, Tricare formerly champus VA or Military, Alaska native, Indian health service, tribal health services, Some other source, None No coverage).

\section{Race}

Race was collected as a categorical variable and provided in the dataset via the following categories: (White, Black, Hispanic, Other (Asian, American Indian or Alaskan Native, Native Hawaiian or others Pacific Islander, others race, multiracial).

\section{Dependent variables}

Mammogram screening was collected as a categorical variable and provided in the dataset via the following categories: (Have You Ever Had a Mammogram: Yes and No).

\section{Results}

After cleaning and screening the data, the final sample for this analysis included 16,147 female participants aged between 40 and 74 years. Most of the participants were married (58.2\%), had less than a 4 year college degree $(61.1 \%)$ were employed for wages $(40.5 \%)$ or retired $(30.0 \%)$, had an income of less than $\$ 75,000$ (58.4), had a mammogram in the past two years $(76.1 \%)$, were White, non-Hispanic 
(78.1\%), and had a healthcare plan purchased through an employer or union (44.9\%). Detailed demographic data can be seen in Table 1. 
Table 1

Participant Demographics ( $N=16,147)$

\begin{tabular}{|c|c|c|}
\hline Variables & Frequency & Percentage \\
\hline \multicolumn{3}{|l|}{ Age } \\
\hline $40-44$ & 1376 & 8.5 \\
\hline $45-49$ & 1660 & 10.3 \\
\hline $50-54$ & 2005 & 12.4 \\
\hline $55-59$ & 2556 & 15.8 \\
\hline $60-64$ & 2774 & 17.2 \\
\hline $65-69$ & 3081 & 19.1 \\
\hline $70-74$ & 2695 & 16.7 \\
\hline \multicolumn{3}{|l|}{ Marital Status } \\
\hline Married & 9398 & 58.2 \\
\hline Divorced & 2880 & 17.8 \\
\hline Widowed & 1920 & 11.9 \\
\hline Separated & 398 & 2.5 \\
\hline Never married & 1201 & 7.4 \\
\hline A Member of an Unmarried Couple & 297 & 1.8 \\
\hline Refused & 53 & 0.3 \\
\hline \multicolumn{3}{|l|}{ Education Level } \\
\hline Never Attended School or Only Kindergarten & 8 & 0.0 \\
\hline Grades 1-8 (Elementary) & 282 & 1.7 \\
\hline Grades 9-11 (Some High School) & 789 & 4.9 \\
\hline Grade 12 or GED (High School Graduate) & 4143 & 25.7 \\
\hline College 1-3 Years (Some College or Technical School) & 4646 & 28.8 \\
\hline College 4 Years or More (College Graduate) & 6259 & 38.8 \\
\hline Refused & 20 & 0.1 \\
\hline \multicolumn{3}{|l|}{ Employment Status } \\
\hline Employed for Wages & 6537 & 40.5 \\
\hline Self Employed & 1190 & 7.4 \\
\hline
\end{tabular}




\begin{tabular}{|c|c|c|}
\hline Variables & Frequency & Percentage \\
\hline Out of Work for 1 Year or More & 227 & 1.4 \\
\hline Out of Work for Less Than 1 Year & 176 & 1.1 \\
\hline A Homemaker & 1079 & 6.7 \\
\hline A Student & 35 & 0.2 \\
\hline Retired & 4848 & 30.0 \\
\hline Unable to Work & 1999 & 12.4 \\
\hline Refused & 56 & 0.3 \\
\hline \multicolumn{3}{|l|}{ Income Level } \\
\hline Less Than $\$ 10,000$ & 722 & 4.5 \\
\hline Less Than $\$ 15,000(\$ 10,000$ To Less Than $\$ 15,000)$ & 808 & 5.0 \\
\hline Less Than $\$ 20,000(\$ 15,000$ To Less Than $\$ 20,000)$ & 1014 & 6.3 \\
\hline Less Than $\$ 25,000(\$ 20,000$ To Less Than $\$ 25,000)$ & 1236 & 7.7 \\
\hline Less Than $\$ 35,000(\$ 25,000$ To Less Than $\$ 35,000)$ & 1357 & 8.4 \\
\hline Less Than $\$ 50,000(\$ 35,000$ To Less Than $\$ 50,000)$ & 1954 & 12.1 \\
\hline Less Than $\$ 75,000(\$ 50,000$ To Less Than $\$ 75,000)$ & 2324 & 14.4 \\
\hline$\$ 75,000$ Or More & 4627 & 28.7 \\
\hline Don't Know / Not Sure & 894 & 5.5 \\
\hline Refused & 1211 & 7.5 \\
\hline \multicolumn{3}{|l|}{ Had Mammogram } \\
\hline Yes & 12283 & 76.1 \\
\hline No & 3864 & 23.9 \\
\hline \multicolumn{3}{|l|}{ Race } \\
\hline White Only, Non-Hispanic & 12618 & 78.1 \\
\hline Black Only, Non-Hispanic & 1973 & 12.2 \\
\hline American Indian or Alaskan Native Only, Non-Hispanic & 301 & 1.9 \\
\hline Asian Only, Non-Hispanic & 71 & 0.4 \\
\hline Native Hawaiian or Other Pacific Islander Only, Non-Hispanic & 8 & 0.0 \\
\hline Other Race Only, Non-Hispanic & 57 & 0.4 \\
\hline
\end{tabular}




\begin{tabular}{|lll|}
\hline Variables & Frequency & Percentage \\
\hline Multiracial, Non-Hispanic & 182 & 1.1 \\
\hline Hispanic & 937 & 5.8 \\
\hline Health Coverage & & \\
\hline A Plan Purchased Through an Employer or Union & 7251 & 44.9 \\
\hline A Plan That You or Another Family Member Buys on Your Own & 1809 & 11.2 \\
\hline Medicare & 5293 & 32.8 \\
\hline Medicaid or Other State Program & 1315 & 8.1 \\
\hline Tricare (Formerly Champus), VA, or Military & 372 & 2.3 \\
\hline Alaska Native, Indian Health Service, Tribal Health Services & 107 & 0.7 \\
\hline
\end{tabular}

\section{Race and Mammogram}

A significant relationship between race and having a mammogram in the past two years was found $(\chi 2(6)=92.06, p<0.01)$. The detailed results of the chi square analysis are found in Table 2 below.

Table 2

Participants Who Had a Mammogram in The Past 2 Years $(N=16,147)$ by Race.

\begin{tabular}{|lll|}
\hline Race & Yes (\%) & No (\%) \\
\hline White Only, Non-Hispanic & $9,577(75.9)$ & $3,041(24.1)$ \\
\hline Black Only, Non-Hispanic & $1631(82.7)$ & $342(17.3)$ \\
\hline American Indian or Alaskan Native Only, Non-Hispanic & $198(65.8)$ & $103(34.2)$ \\
\hline Asian Only, Non-Hispanic & $47(66.2)$ & $24(33.8)$ \\
\hline Native Hawaiian or Other Pacific Islander Only, Non-Hispanic & $5(62.5)$ & $3(37.5)$ \\
\hline Other Race Only, Non-Hispanic & $40(70.2)$ & $17(29.8)$ \\
\hline Multiracial, Non-Hispanic & $130(71.4)$ & $52(28.6)$ \\
\hline Hispanic & $655(69.9)$ & $282(30.1)$ \\
\hline Note. X2(7) = 92.29, p<0.01 & & \\
\hline
\end{tabular}

\section{Healthcare Coverage and Mammogram}

A significant relationship between healthcare coverage and whether participants had a mammogram in the past two years was found $(\chi 2(5)=84.00, p<0.01)$. The detailed results of the chi square analysis are found in Table 3 below. 
Table 3

Participants Who Had a Mammogram in The Past 2 Years $(N=16,147)$ by Health Coverage

\begin{tabular}{|c|c|c|c|}
\hline \multirow[t]{2}{*}{ Variables } & \multicolumn{3}{|c|}{$\begin{array}{l}\text { Women Respondents Aged } 40-74 \text { Who Have Had } \\
\text { Mammogram in The Past } 2 \text { Years }\end{array}$} \\
\hline & Yes & No & Total \\
\hline $\begin{array}{l}\text { A Plan Purchased Through an Employer } \\
\text { or Union }\end{array}$ & $5,620(77.5)$ & $1,631(22.5)$ & $7,251(100.0)$ \\
\hline $\begin{array}{l}\text { A Plan That You or Another Family } \\
\text { Member Buys on Your Own }\end{array}$ & $1,338(74.0)$ & $471(26.0)$ & $1,809(100.0)$ \\
\hline Medicare & $4,086(77.2)$ & $1,207(22.8)$ & $5,293(100.0)$ \\
\hline Medicaid or Other State Program & $877(66.7)$ & $438(33.3)$ & $1315(100.0)$ \\
\hline $\begin{array}{l}\text { Tricare (Formerly Champus), VA, Or } \\
\text { Military }\end{array}$ & $289(77.7)$ & $83(23.3)$ & $372(100.0)$ \\
\hline $\begin{array}{l}\text { Alaska Native, Indian Health Service, } \\
\text { Tribal Health Services }\end{array}$ & $73(68.2)$ & $34(31.8)$ & $107(100.0)$ \\
\hline Total & $12,283(76.1)$ & $3,864(23.9)$ & $16,147(100.0)$ \\
\hline Note. $\chi 2(5)=84.00, p<0.01$ & & & \\
\hline
\end{tabular}

A logistic regression was performed to assess the impact of race on the likelihood of having a mammogram performed in the past two years. The full model contained one independent variable (race) with eight categories. The full model containing all predictor variables was statistically significant ( $\chi 2(7)$ $=92.29, \mathrm{p}<0.01)$. The model as a whole explained $1.0 \%$ (Nagelkerke R 2 ) of the variance in mammograms performed in the past two years and correctly classified $76.1 \%$ of cases. As shown in Table 4, only three races made a unique statistically significant contribution to the model. However, the odds ratio indicated that Black only - non-Hispanic and American Indian or Alaskan native only nonHispanics were less likely to have a mammogram in the past two years when compared to White only, non-Hispanics. 
Table 4

Logistic Regression Results for Race on Mammography

\begin{tabular}{|c|c|c|c|c|}
\hline \multicolumn{2}{|c|}{ Variables } & \multirow{2}{*}{$\begin{array}{l}\text { B } \\
-1.16\end{array}$} & \multirow{2}{*}{$\begin{array}{l}\text { S.E. } \\
0.02\end{array}$} & \multirow{2}{*}{$\begin{array}{l}\operatorname{Exp}(\mathrm{B}) \\
0.32\end{array}$} \\
\hline Step 0 & Constant & & & \\
\hline \multirow[t]{9}{*}{ Step 1} & White Only, Non-Hispanic & & & \\
\hline & Black Only, Non-Hispanic & -0.30 & 0.07 & $0.74 *$ \\
\hline & American Indian or Alaskan Native Only, Non-Hispanic & -0.72 & 0.09 & $0.49 *$ \\
\hline & Asian Only, Non-Hispanic & 0.19 & 0.14 & 1.21 \\
\hline & Native Hawaiian or Other Pacific Islander Only, Non-Hispanic & 0.17 & 0.26 & 1.19 \\
\hline & Other Race Only, Non-Hispanic & 0.33 & 0.73 & 1.39 \\
\hline & Multiracial, Non-Hispanic & -0.01 & 0.30 & 0.99 \\
\hline & Hispanic & -0.07 & 0.18 & 0.93 \\
\hline & Constant & -0.84 & 0.07 & 0.43 \\
\hline
\end{tabular}

\section{Logistic Regression Results for Race on Mammography}

A logistic regression was performed to assess the impact of Health Coverage on the likelihood that participants had a mammogram performed in the past two years. The full model contained one independent variable (health coverage) with six categories. The full model containing all predictor variables was statistically significant $(\chi 2(5)=84.00, p<0.01)$. The model as a whole explained $.07 \%$ (Nagelkerke R 2) of the variance in mammograms performed in the past two years and correctly classified $76.1 \%$ of cases. As indicated in Table 5, only two health coverage plans made a unique statistically significant contribution to the model. However, the odds ratio indicated that participants with a plan that they or another family member bought on their own and participants with Medicaid or other state program were less likely to have a mammogram in the past two years when compared to participants who had a plan purchased through an employer or union. 
Table 5

Logistic Regression Results for Race on Mammograms

\begin{tabular}{|lllll|}
\hline Variables & B & S.E. & Exp(B) \\
\hline Step 0 & Constant & -1.16 & 0.02 & 0.32 \\
\hline Step 1 & A Plan Purchased Through an Employer or Union & & & \\
\cline { 2 - 5 } & A Plan That You or Another Family Member Buys on Your Own & -0.47 & 0.21 & $0.62^{*}$ \\
\cline { 2 - 5 } & Medicare & -0.28 & 0.21 & 0.76 \\
\hline Medicaid or Other State Program & -0.46 & 0.21 & $0.63^{*}$ \\
\hline Tricare (Formerly Champus), VA, Or Military & 0.07 & 0.22 & 1.07 \\
\hline Alaska Native, Indian Health Service, Tribal Health Services & -0.48 & 0.24 & 0.62 \\
\hline Constant & -0.76 & 0.21 & 0.47 \\
\hline
\end{tabular}

\section{Logistic Regression Results for Race and Health Coverage on Mammograms}

A logistic regression was performed to assess the impact of race and health coverage on the likelihood that participants had a mammogram performed in the past two years. The full model contained two independent variables: race with eight categories and health coverage with six categories. The full model containing all predictor variables was statistically significant $(\chi 2(12)=166.53, p<0.01)$. The model explained $2.0 \%$ (Nagelkerke $\mathrm{R}^{2}$ ) of the variance in mammograms performed in the past two years and correctly classified $76.1 \%$ of cases. As shown in Table 6, only two races made a unique statistically significant contribution to the model. This indicates that White only, non-Hispanics were 1.25 times more likely and Black only, non-Hispanics were 1.98 times more likely to have a mammogram in the past two years compared to participants from other racial and ethnic groups. 
Table 6

Logistic Regression Results for Race and Health Coverage on Mammograms

\begin{tabular}{|c|c|c|c|c|}
\hline \multicolumn{2}{|r|}{$\begin{array}{l}\text { Women Respondents Aged } 40-74 \text { Who Have Had Mammogram in The } \\
\text { Past } 2 \text { Years }\end{array}$} & \multirow{2}{*}{$\begin{array}{l}\text { B } \\
0.92\end{array}$} & \multirow{2}{*}{$\begin{array}{l}\text { Std. } \\
\text { Error } \\
0.26\end{array}$} & \multirow[t]{2}{*}{$\operatorname{Exp}(B)$} \\
\hline Yes & Intercept & & & \\
\hline & White Only, Non-Hispanic & 0.22 & 0.08 & $1.25^{\star}$ \\
\hline & Black Only, Non-Hispanic & 0.68 & 0.09 & $1.98^{*}$ \\
\hline & American Indian or Alaskan Native Only, Non-Hispanic & -0.19 & 0.16 & 0.83 \\
\hline & Asian Only, Non-Hispanic & -0.28 & 0.26 & 0.76 \\
\hline & Native Hawaiian or Other Pacific Islander Only, Non-Hispanic & -0.45 & 0.73 & 0.64 \\
\hline & Other Race Only, Non-Hispanic & -0.02 & 0.30 & 0.98 \\
\hline & Multiracial, Non-Hispanic & 0.03 & 0.18 & 1.03 \\
\hline & Hispanic & $0^{\mathrm{b}}$ & & \\
\hline & A Plan Purchased Through an Employer or Union & 0.08 & 0.25 & 1.08 \\
\hline & A Plan That You or Another Family Member Buys on Your Own & -0.12 & 0.25 & 0.89 \\
\hline & Medicare & 0.05 & 0.25 & 1.05 \\
\hline & Medicaid or Other State Program & -0.47 & 0.25 & 0.62 \\
\hline & Tricare (Formerly Champus), VA, Or Military & 0.07 & 0.28 & 1.07 \\
\hline & Alaska Native, Indian Health Service, Tribal Health Services & 0 & & \\
\hline
\end{tabular}

\section{Discussion}

The current study revealed a relationship between obtaining mammography screening and multiple factors including race and lack of adequate health insurance coverage. Regular screening for breast cancer, including annual mammograms and breast exams by a qualified medical expert is crucial for early detection of breast cancer ${ }^{2}$. However, the social determinants of health such as age, race, income, and insurance status are impediments that could constitute barriers to carrying out the recommended guidelines for screening. Social determinants of health are influential factors of healthcare utilization and this association has been demonstrated in the literature previously $7 ; 8$. Since the findings of the present investigation were obtained by using a large national sample exploiting data from a national survey (BRFSS) with known higher response rates, there is a smaller margin of error in examining relationships for hard to reach populations such as minorities. In addition, the random sampling of the participants via random digit dialing from commercially available phone lists increases the generalization of the results. 
Hence, the sample is representative of the larger national populations and is less likely to be subject to bias.

\section{Race and Mammogram}

This analysis found a significant relationship between race and having a mammogram. Black women were less like to have a mammogram in the past two years when compared to other races. Existing evidence indicates that racial and ethnic minority women are prone to experience delays in treatment, as well as lower than recommended rates of mammogram screening ${ }^{9}$. This delay in diagnosis and treatment for black women leads to an increased rate of diagnosis at a later-stage breast cancer and subsequently leads to an increased morbidity and mortality rates ${ }^{8}$.

\section{Insurance status and Mammogram}

The role of adequate insurance coverage was identified in this study as important in access to Mammogram screening. Women having employer or union purchased health insurance coverage were more likely to have a mammogram in the past two years when compared to women who were underinsured through state or state subsidized insurance programs. This finding supports currently available literature linking social determinants of health with preventative screening ${ }^{9}$. The findings of this analysis are consistent with the findings of a retrospective chart review of 157 women ages 40-75 years ${ }^{10}$. Of the patients who were able to get their screening mammograms performed in Khali and colleagues 'study, $84.5 \%$ utilized BRIDGE healthcare clinic's program (student-run free clinics). Therefore, this study substantiated the evidence that volunteer providers such as student-run free clinics play an essential part in expanding uninsured patients' access to mammograms. Consequently, facilitating access to care and increasing access to payment for breast cancer screening through innovative programs may be linked with screening mammography compliance and subsequently earlier diagnosis of breast cancer ${ }^{11}$. Thus, healthcare coverage and accessibility are essential tools required for successful health prevention campaigns ${ }^{10}$.

\section{Race, Insurance Status, and Mammogram}

The combined impact of race and adequate insurance coverage was found to be significant with having a mammogram. While a secured source of health coverage increased the prospect of having a mammogram, race was also important. White women and their Black counterparts were more likely to have a mammogram when compared to other races. Similarly, in a previously published systematic review, White women were more likely to have adequate health insurance coverage when compared to other ethnic minority women ${ }^{11}$. This investigation has provided evidence that obtaining a screening mammography exam is related to both race and insurance coverage. Hence, a major role in healthcare accessibility such as paying for recommended healthcare services can be financially draining for individuals with income scarcity and lack of adequate health insurance coverage. Thus, having access to care and having an adequate insurance coverage may be linked with the likelihood of getting a screening mammography and consequently earlier diagnosis of breast cancer ${ }^{11}$. 


\section{Social Determinants of Health}

These findings support that the social determinants of health such as marital status, education, employment, and having adequate health insurance may be important related to having screening mammography. As it was established in prior research, these social determinant aspects were found to be prominent factors of healthcare utilization ${ }^{12 ; 13}$. Comparably to the findings of the existing study, being married, having a university education were among positive predictors for mammography uptake $(66.8 \%)^{14}$. Likewise, another study revealed participants with a higher education were significantly more likely to adhere to the recommendations of breast cancer screenings ${ }^{15}$. Similarly, published evidence that employment was also a determining factor for participating in mammogram ${ }^{16}$. Moreover, having a usual source of healthcare and a woman's geographical location were associated with timely screening mammography ${ }^{9}$. Having a consistent source of care increased the likelihood of acquiring preventive health education and an annual breast cancer screening as recommended ${ }^{17}$. Furthermore, women of color differ from their White counterparts in the degree to which increasing socioeconomic resources is correlated with increasing cancer screening utilization ${ }^{18}$.

\section{Future Clinical and Research Implications}

Breast health awareness is a fundamental part of health promotion and a key factor in early stage breast cancer detection. However, the importance of a yearly screening mammogram remains limited and not adequately practiced among minority women who lack consistent health insurance. Factors such as ethnicity, socio-economic status, and geographical location are influential assessment findings to be considered. For clinicians, assessing for these social determinants of health may contribute to mammography adherence. Assisting women to overcome these barriers may increase breast cancer screening and early detection. In addition, providing education about an individual risks and barriers to obtaining screening and subsequent treatment could also increase the mammography adherence rates and early intervention if needed.

As per the Association of Women's Health, Obstetric and Neonatal Nurses' (AWHONN) advocacy and recommendations, it is necessary to provide resources and education to women's health nurses so they can be better equipped to assist female patients with their breast health ${ }^{19}$. Subsequently, taking into consideration the particularities presented by each participant, and proactively encouraging individuals on the health advantages of cancer preventive services could raise awareness and consequently improve mammogram screening rates ${ }^{9}$. Future policy work should focus on finding means to expand healthcare accessibility and involvement in disadvantaged populations. Breast cancer awareness can be improved and eventually breast cancer disparity reduced by developing a community-based participatory approach and a culturally responsive breast cancer screening program ${ }^{20 ; 21}$. Through their contribution, practicing nurses empower women by encouraging them to take active roles in monitoring their own breast health. Therefore, practicing nurses assist in improving outcomes of care, and simultaneously contribute in shrinking the gap and apparent disparity in cancer diagnosing and treatment ${ }^{19}$. Healthcare providers' 
counseling and suggestions about mammogram screening and recommended national guidelines ${ }^{9}$ serve as a preliminary point for exploring some of the socio-demographic, health-related, and circumstantial characteristics that obstruct timely screening mammography ${ }^{22}$. Future research should continue to focus on the impact of social determinants of health on access and outcomes of care.

\section{Limitations}

Although the BRFSS dataset is a sizeable nationwide representative sample, this study does have shortcomings. Using the BRFSS dataset, to conduct a secondary analysis constrained the investigator to the sampling measures and the data at hand. The cross-sectional design limits establishing any causal relationships between Race, Health Insurance Coverage, and Breast Cancer Screening. Since the BRFSS is a telephone survey, potential participants who live in households without telephone coverage, may be excluded. Furthermore, The BRFSS relies on self-reported data obtained from the participants which may be sources of possible error that could result in some misclassification of the variables: age, race, education, income, employment, primary health insurance coverage, and mammogram screening.

\section{Conclusion}

This study discovers that race and insurance status have an impact on breast cancer screening. The results of this study provide further evidence that having health insurance coverage facilitates access to preventive care for women. Since mammography screening rates continue to be lower than recommended in patients with low socioeconomic status, these results will be foundational to a developing a program of research focused on increasing access to care and eliminating healthcare disparity in ethnic minority women with breast cancer. Identifying and understanding these influences will be key to the development of interventions aimed at increasing healthcare availability in this population. Through individualized patients 'care plans, education, and awareness, practicing nurses can empower racial and ethnic minority women to adhere to their recommended yearly mammography screening guidelines.

Clinical Resources:

- Association of Women's Health, Obstetric and Neonatal Nurses.

DOl:https://doi.org/10.1016/j.jogn.2017.07.001

- Center for Disease, C., \& Prevention. (2018, 2019-12-09T02:56:18Z). CDC - 2018

https://www.cdc.gov/brfss/annual_data/annual_2018.html

- Recommendations From the ACR Commission on Breast Imaging. J Am Coll Radiol, 14(9), 11371143.

https://doi.org/10.1016/j.jacr.2017.06.001

\section{Declarations}




\section{Ethics approval and consent to participate:}

Not applicable.

\section{Consent for publication:}

Not applicable.

\section{Availability of data and materials}

The 2018 BRFSS dataset was used. Available at:

https://www.cdc.gov/brfss/annual_data/annual_2018.html

\section{Competing interests:}

The authors declare that they have no competing interest regarding the publication of this paper.

\section{Funding:}

None

\section{Authors' contributions:}

The authors (SY, JM, and LAT) confirm their contribution to the paper as follows:

SY wrote the main manuscript text and substantially contributed through the acquisition and analysis of the data. SY and JM substantially contributed by drafting the manuscript and design of the study. SY and JM substantially contributed to the interpretation of the results. JM and LAT edited and revised the article critically for important intellectual content and approved the version to be published.

\section{Acknowledgements:}

The authors appreciatively acknowledge West Virginia University for the unceasing support, the constructive feedback and recommendations of the editor and reviewers which were very helpful to improve the quality of the article.

\section{Authors' information:}

\section{Salamata Yoda*, FNP-BC, MSN, BSN, Sigma Theta Tau International chapter}

School of Nursing, West Virginia University, Morgantown, WV, USA

Phone: 646-510-7163. Fax: 718-960-1052. Email: *sy00001@mix.wvu.edu

Salamata Yoda ORCID iD URL: https://orcid.org/0000-0003-1550-2604 
Jennifer Mallow, FNP-BC, PhD, MSN, BSN, Sigma Theta Tau International chapter,

Associate Professor, School of Nursing, West Virginia University, Morgantown, WV, USA

Phone: 304-293-1402. Fax: 304-293-6826. Email: jamallow@hsc.wvu.edu

Address: PO Box 9600 Robert C. Byrd Health Sciences Center 1 Medical Center Drive Room 6517 Morgantown, WV 26506-9600

Laurie A. Theeke, FNP-BC, PhD, MSN, BSN, GCNS-BC, FAAN, Sigma Theta Tau International chapter, Director PhD Program, School of Nursing, West Virginia University, Morgantown, WV, USA. Phone: 304293-1405. Fax: 304-293-6826.

Email: Itheeke@hsc.wvu.edu. Address: PO Box 9600: 1 Medical Center Drive, PO Box 9620Room 6621 Morgantown, WV 26506-9600

\section{Corresponding author:}

Correspondence to Salamata Yoda

\section{References}

1. DeSantis, C. E., Ma, J., Gaudet, M. M., Newman, L. A., Miller, K. D., Goding Sauer, A., Jemal, A., \& Siegel, R. L. (2019). Breast cancer statistics, 2019. CA: a cancer journal for clinicians, 69(6), 438451.

2. Monticciolo, D. L. (2020, Oct). Current Guidelines and Gaps in Breast Cancer Screening. J Am Coll Radiol, 17(10), 1269-1275. https://doi.org/10.1016/j.jacr.2020.05.002

3. Lehman, C. D., Arao, R. F., Sprague, B. L., Lee, J. M., Buist, D. S., Kerlikowske, K., Henderson, L. M., Onega, T., Tosteson, A. N., Rauscher, G. H., \& Miglioretti, D. L. (2017, Apr). National Performance Benchmarks for Modern Screening Digital Mammography: Update from the Breast Cancer Surveillance Consortium. Radiology, 283(1), 49-58. https://doi.org/10.1148/radiol.2016161174

4. Talley, C. H., Yang, L., \& Williams, K. P. (2017). Breast cancer screening paved with good intentions: Application of the information-motivation-behavioral skills model to racial/ethnic minority women. Journal of Immigrant and Minority Health, 19(6), 1362-1371.

5. Ko, N. Y., Hong, S., Winn, R. A., \& Calip, G. S. (2020, Mar 1). Association of Insurance Status and Racial Disparities With the Detection of Early-Stage Breast Cancer. JAMA Oncol, 6(3), 385-392. https://doi.org/10.1001/jamaoncol.2019.5672

6. Center for Disease, C., \& Prevention. (2018, 2019-12-09T02:56:18Z). CDC - 2018 BRFSS Survey Data and Documentation. https://www.cdc.gov/brfss/annual_data/annual_2018.html

7. Womeodu, R. J., \& Bailey, J. E. (1996, Jan). Barriers to cancer screening. Med Clin North Am, 80(1), 115-133. https://doi.org/10.1016/s0025-7125(05)70430-2 
8. Yedjou, C. G., Tchounwou, P. B., Payton, M., Miele, L., Fonseca, D. D., Lowe, L., \& Alo, R. A. (2017). Assessing the racial and ethnic disparities in breast cancer mortality in the United States. International journal of environmental research and public health, 14(5), 486.

9. Wang, K., Thompson, T., Galusha, D., Friedman, H., Nazario, C., Nunez, M., Maharaj, R., Adams, O., \& Nunez-Smith, M. (2018). Non-communicable chronic diseases and timely breast cancer screening among women of the Eastern Caribbean Health Outcomes Research Network (ECHORN) Cohort Study. Cancer Causes \& Control, 29(3), 315-324.

10. Khalil, S., Hatch, L., Price, C. R., Palakurty, S. H., Simoneit, E., Radisic, A., Pargas, A., Shetty, I., Lyman, M., \& Couchot, P. (2019). Addressing Breast Cancer Screening Disparities Among Uninsured and Insured Patients: A Student-Run Free Clinic Initiative. Journal of Community Health, 1-5.

11. Ko, N. Y., Hong, S., Winn, R. A., \& Calip, G. S. (2020). Association of insurance status and racial disparities with the detection of early-stage breast cancer. JAMA oncology, 6(3), 385-392.

12. Coughlin, S. S. (2019). Social determinants of breast cancer risk, stage, and survival. Breast cancer research and treatment, 177(3), 537-548.

13. Patel, K., Kanu, M., Liu, J., Bond, B., Brown, E., Williams, E., Theriot, R., Bailey, S., Sanderson, M., \& Hargreaves, M. (2014, Oct). Factors influencing breast cancer screening in low-income African Americans in Tennessee. J Community Health, 39(5), 943-950. https://doi.org/10.1007/s10900-0149834-x

14. Zamorano-Leon, J. J., López-de-Andres, A., Álvarez-González, A., Astasio-Arbiza, P., López-Farré, A. J., de-Miguel-Diez, J., \& Jiménez-García, R. (2020). Reduction from 2011 to 2017 in adherence to breast cancer screening and non-improvement in the uptake of cervical cancer screening among women living in Spain. Maturitas, 135, 27-33.

15. Guo, Y., Cheng, T. C., \& Yun Lee, H. (2019). Factors associated with adherence to preventive breast cancer screenings among middle-aged African American women. Social work in public health, 34(7), 646-656.

16. Ogunsiji, O. O., Kwok, C., \& Fan, L. C. (2017). Breast cancer screening practices of African migrant women in Australia: a descriptive cross-sectional study. BMC women's health, 17(1), 1-10.

17. Oeffinger, K. C., Fontham, E. T., Etzioni, R., Herzig, A., Michaelson, J. S., Shih, Y.-C. T., Walter, L. C., Church, T. R., Flowers, C. R., \& LaMonte, S. J. (2015). Breast cancer screening for women at average risk: 2015 guideline update from the American Cancer Society. Jama, 314(15), 1599-1614.

18. Monnat, S. M. (2014). Race/ethnicity and the socioeconomic status gradient in women's cancer screening utilization: A case of diminishing returns? Journal of health care for the poor and underserved, 25(1), 332.

19. Executive, A. (2017). Breast Cancer Screening.

20. Ka'opua, L. S. (2008, Aug). Developing a culturally responsive breast cancer screening promotion with Native Hawaiian women in churches. Health Soc Work, 33(3), 169-177.

https://doi.org/10.1093/hsw/33.3.169 
21. Cardarelli, K., Jackson, R., Martin, M., Linnear, K., Lopez, R., Senteio, C., Weaver, P., Hill, A., Banda, J., \& Epperson-Brown, M. (2011). Community-based participatory approach to reduce breast cancer disparities in south Dallas. Progress in community health partnerships: research, education, and action, 5(4), 375.

22. White, A., Thompson, T. D., White, M. C., Sabatino, S. A., de Moor, J., Doria-Rose, P. V., Geiger, A. M., \& Richardson, L. C. (2017). Cancer screening test use-United States, 2015. MMWR. Morbidity and mortality weekly report, 66(8), 201. 